\title{
Analysis on the University Chinese Teaching and Cultivation of Humane Quality
}

\author{
Dalun Zhu, Cuibai Hu
}

Nanchang Institute of Science \&Technology, Nanchang Jiangxi 330108, China

\section{Keywords: College Chinese; Humanistic quality; Emotional education}

\begin{abstract}
In the higher education, the quality education of college students is becoming more and more important. College Chinese teaching plays an irreplaceable role in cultivating students' humanistic quality. However, it is still not enough to pay attention to the humanistic quality education in colleges and universities, and there are still some problems in the practice teaching process of the humanistic quality was slipping down. Through an analysis of the problems in Chinese teaching, to explore humanistic factors in teaching, by means of the reform of teaching methods, the positioning of college Chinese teaching function, strengthen the teaching of college Chinese on the importance and significance of cultivating college students' humane quality.
\end{abstract}

\section{Introduction}

Colleges and universities have always been an important position in the creation, integration and sublimation of human spirit, college students shoulder the historical mission of carrying forward the national culture, In addition to learning a wealth of knowledge, skills, but also intellectuals should have feelings, have a good cultural quality, the future of the motherland, the destiny of mankind as their own responsibility. Humanistic quality education is through pass on knowledge, knowledge accumulation and environmental impact, the human outstanding cultural achievements to enhance humanistic individual personality, temperament and accomplishment, become a kind of stable inner quality that is emitted from the inside out. Unfortunately, colleges and universities in the humanities education emphasis is still not enough, there are still problems in the practice teaching, education and training effect to landslide in the process of college Students' humanistic quality appeared.

\section{The present situation of Chinese college students' Humanistic Quality.}

Self consciousness is too strong and lack of humanistic values. In Colleges and universities, a considerable number of college students in the behavior of the traditional sense of good, evil, beauty and ugliness are distorted, resulting in the dislocation of traditional standards and daily words and deeds. The daily life of uncivilized behavior occurs; lazy life, sense of discipline; in the process of interpersonal communication, excessive pursuit of the liberation of personality, ego; self-centered, lack of basic ability to distinguish things; psychological quality is poor, they are prone to excess, they lack of stable cognition of the meaning of life. By social public opinion scale disease, lead to the concern and reflection on the lack of humanistic quality of contemporary college students.

National consciousness is weakened, lack of national culture identity. The formation of China civilization for thousands of years the development of the Chinese nation outstanding knowledge of the humanities, history, magnificent culture and technology development in the history of the world 
civilization created a brilliant chapter, produced a higher impact and positive significance for the later development. But as a contemporary, the students are poorly understood, in recent years, In recent years, compared with the popularity of China, pursue and admire Japan and South Korea style, Europe and the United States style, China's excellent classical culture fade out of college vision, lead to the weakening of college students' national consciousness, lack of the identity of national culture and spirit.

Lack of humanistic knowledge, lack of internal human literacy. For a long time, the mode of examination oriented education has resulted in the basic education, the goal of education is clear, that is, to develop a specific professional or field of useful. Simple teaching teachers focus only on knowledge, ignoring the enlightening education of students' comprehensive quality and guide the promotion, ignoring the popularity of traditional culture concept; in effect the whole examination environment, students are more passive with professional knowledge and skills, which leads to students' humanistic knowledge lack of knowledge, concept of the humanities sentiment less. Not formed from the inside exudes a stable, the overall quality of the individual. For some college students, although there is a certain level of knowledge and technology, but the knowledge of them is narrow, personal comprehensive literacy needs to be improved, especially in the humanities need to strengthen self learning.

Value orientation utilitarian myopia, lack of long-term goals in life. Some college students do not have long-term plans and goals of their individual value orientation, utilitarian, lack of self ideal cognitive belief and realize their ideals; lack of social responsibility, for the nation, does not have the correct and positive contribution to the society in order to spirit; The realization of self interests and goals, regardless of the interests of others and society, worship the concept of money, such as the wrong values. Embodied in the professional choice, only select the good future , good professional, but not selection with their own interests and talents; in the course of study, just choose to learn useful courses for their professional careers; in the process, there is no long-term occupation planning, ignoring the realization of self value, lack of initiative and long-term in order to get the diploma consciousness, mix education as the starting point, to get to the pursuit of short-term interests, not to consider the long-term development. There are a lot of college students in the university life of aimless, deviate from their own direction of development, heavy wine in entertainment, lost self, loss of life goals.

\section{The feasibility of the combination of college Chinese teaching and humanistic quality training.}

Chinese education has the basic characteristics of humanity. Chinese education is not only training for the students spoken and written ability, it is more important in the process of Chinese learning, culture history, humanities knowledge and humanities of people's spirit to enhance the role and art appreciation ability, and cultivate rich personality. Chinese education is not utilitarian, short-sighted, but a long-term, comprehensive education, cultivation imperceptibly, so that everyone in the language learning process, slowly precipitate out of a temperament, dip emotional personality and sound of the atmosphere and taste, form a rich spirit world and a positive outlook on life and values.

Chinese teaching from content to form full of humanistic spirit. The development of language is the history of the development of a nation's culture. The teaching of language in Chinese teaching has already embodied the inheritance and development of rich humanistic spirit. The literary work is reflected in a specific period of social life and the humanistic spirit, which is the expression of the author's thoughts and feelings, is the increasing awareness of human and nature, human and society, 
human development, is a profound understanding of human nature, human rights, humanitarian and life, full of humanistic spirit. In literary works, we can understand the history and the life, and improve the understanding of the meaning of life. In the process of Chinese teaching, teachers teach students, is not only a passive acceptance, but also the interaction the language behavior between teachers and students, is teaching and educating people together, grow together, is a process of teaching benefits teachers as well as students. between teachers and students interaction is in strong humanistic conception and environment, is between the teachers and students emotion and thought the agreement and unification, in this agreement and unification, cultural inheritance and communication in Chinese teaching, to moisten things silently, cultivate students' personality and mind realm, knowledge and other humanities.

\section{Problems in the cultivation of humanistic quality in college Chinese Teaching.}

The decline of Chinese teaching in the university curriculum design. At present, the management department of university education in our country lack attention to the necessary of college Chinese teaching, especially neglect significance of the Chinese teaching activities to enhance students' humanistic quality ability, though the university curriculum design into the senior high school entrance examination of college Chinese courses, but the University Chinese is gradually the tendency to be marginalized. From an academic point of view, college Chinese is a public course, not an independent discipline. As a professional public elective courses, elective students have the right in the face of this embarrassing situation, college Chinese teachers do not put more effort in the teaching activities, but hold a perfunctory attitude, not from the humanistic quality education of college students to consider the development of college Chinese teaching work. College Chinese teaching is just a simple explanation of literary works, not to stimulate students to explore the meaning behind the literary works, students also lack of interest in this regard. In the course of the University, most of the courses are designed as elective courses, even if they are used as a specialized course, the teaching materials are not uniform. Moreover, the content of teaching materials is old, the theory and practice are not closely linked, and the sense of time is short. In such a situation, the lack of interest in learning Chinese is not conducive to the cultivation of college students' humanistic quality.

The teaching method is single and the teaching idea is obsolete. At present, our country college Chinese teaching idea and goal of college Chinese teaching deviation, the focus of teachers is the literary works of the academic point of view, the theoretical Chinese for non professional students, the teaching content is too abstract and academic, and public courses in the university language is far from. Under the present condition, the cultivation of the humanistic quality of college students is the proper meaning of the college Chinese teaching, and it is necessary to train the students to grasp the connotation of the classical literary works in different periods. College Chinese teachers should design a scientific and reasonable arrangement of teaching content, using multiple teaching methods, guide students to improve the learning interest of college Chinese, the university language learning, improve knowledge, expand humanities knowledge, so as to enhance the humanistic quality and core competitiveness continuously. However, according to the current our country university Chinese teaching is the traditional teaching modes and methods, only focus on indoctrination teaching cramming, ignoring the characteristics of college students' humanistic quality and the training needs analysis and teaching teachers only pay attention to the three feet of the podium, ignoring the cultivation of college students' interest in learning. 


\section{On the reform of college Chinese teaching and the cultivation of humanistic quality.}

On the reform of College Chinese education to improve the status of college Chinese. College Chinese is a public basic course in colleges and universities, which is not the same as other public basic courses. With the importance of college Chinese education in the cultivation of humanistic quality, many colleges and universities take college Chinese as a compulsory course, and the status of the subject has been improved. However, in the whole curriculum, college Chinese is regarded as a comprehensive discipline, which takes into account the multi-disciplinary content. The connotation of teaching materials and the development of teachers' teaching materials also have an impact on students. It highlights the college Chinese education on college students' humanistic quality plays an important role, should be subject to improve the status of college Chinese is more important position, as a required course in the university, we should carry on the reform from the orientation of the course to the choice of teaching materials and the teaching methods, so as to meet the requirements of the cultivation of college students' humanistic quality.

Focus on teaching students in accordance with their aptitude, teaching methods and teaching materials selection. The student is the main body of the teaching activity participation, the university language education should carry on the reform of the teaching method according to the student humanities accomplishment. In the teaching concept, we should realize that the students have mastered the ability of listening, speaking, reading and writing, and the ability to comprehend the connotation of humanistic spirit through the exam oriented education. So college Chinese education should be carried out in middle school on the basis of teaching, teaching methods should be positioned according to the student's own ability, at the same time, in the selection of teaching materials, should choose according to their cultural level and knowledge background, not all students use the same textbooks, we should pay more attention to the demands of students' comprehensive ability and quality. In the teaching process, to fully realize the college Chinese class less, let the reality in students' professional course learning, College Chinese teachers should carry out classroom design flexible and reasonable, the textbook knowledge deepening development, grasp the teaching link, pay attention to guide and influence on the students in the humanistic quality and scientific quality, and students in a joint study and discussion teaching benefits teachers as well as students., and let the students feel full of humanistic spirit in college Chinese language education, psychological resonance, achieve the humanistic quality cultivation objective.

\section{References:}

[1] Gong X J. College English Teaching and Cultivation of Humane Quality[J]. Journal of Shanxi Agricultural University, 2004..

[2] Hong L U. The University Chinese and the Education of Humane Quality[J]. Journal of Hebei University of Science \& Technology, 2001.

[3] Yuan-Zhen P I. On the Cultivation of Humane in the College Classes[J]. Journal of Changsha University, 2004.

[4] Yang K, Chen W, Min L I, et al. The Study on the Humane Quality Cultivation of Science and Engineering College Students[J]. 2001.

[5] Sun C A. University Chinese and humane quality-oriented education[J]. Journal of Hubei Normal University, 2005. 
[6] Zhu Q X, Zhu C H, Shao W X. Discuss Humane Quality-oriented Education from the Disappearance of Contemporary University Student's Humane Spirit[J]. East China Economic Management, 2006.

[7] Cai J Z. Science Student's Humane Quality-oriented Education In the Information Age[J]. Journal of Yulin Teachers College, 2007.

[8] Ning Z Y, Bin X I, Liu Y Q, et al. The general plan of building university's humane quality-oriented education with saving arranging[J]. Journal of Architectural Education in Institutions of Higher Learning, 2005.

[9] Yi-Jun L U. On the Humane Quality-Oriented Education in Medical Colleges and Universities[J]. Acta Universitatis Medicinalis Nanjing, 2003. 